\title{
Light Transmittance for Films of Liquid Crystalline Polymer having Cyanobiphenyl Group in the Side Chain
}

\author{
Y. Tanaka and Y. Yukimoto \\ Department of Materials Science and Engineering, Faculty of Engineering, University of Fukui, Fukui 910-8507, Japan \\ Fax: 81-(0)776-27-8767, e-mail: tanaka@matse.u-fukui.ac.jp
}

\begin{abstract}
A film sample is prepared for poly(cyanobiphenyl ethylacrylate), abbreviated to PCB2A, to investigate transparent/opaque change in response to thermal history. PCB2A is thermotropic type liquid crystal, the distance is not far between glass transition temperature $\left(T_{\mathrm{g}}\right)$ and the nematic-isotropic transition temperature $\left(T_{\mathrm{N}-\mathrm{I}}\right)$. The kinetics from isotropic to nematic phase strongly depend on the molecular weight $\left(M_{\mathrm{w}}\right) \quad$ If $M_{\mathrm{w}}$ is high, the transition becomes slow dynamics; for example, it takes more than $60 \mathrm{~min}$ from isotropic to nematic phase by the temperature jump. This large time lag enables us to control the transparency of PCB2A film by means of a simple thermal treatment slightly below $T_{\mathrm{N}-\mathrm{I}}$. The results of the measurement of transmitted light volume for films prepared from samples of different $M_{\mathrm{w}}$ can be interpreted in terms of the kinetics of isotropic-nematic phase transition.
\end{abstract}

Key words : Compression Moulding, Light Transmittance, Nematic Glass, Thermal Ageing, Liquid Crystalline Polymer

\section{INTRODUCTION}

Thermotropic liquid crystalline polymers often can form films by the moulding with keeping liquid crystalline properties. Also for poly(cyanobiphenyl) acrylate(PCB2A), the side-chain type liquid crystalline polymer, films of the thickness of approximately $50 \mu \mathrm{m}$, or less, are obtained by the compression moulding. Recently, a very slow transition from isotropic to nematic phase has been found for PCB2A, which can be utilised to control optical properties in the film. For example, it is possible to prepare films having different light transmittance with the light scattering of the nematic phase.[1]

As for films of variable light transmittance, many research works are currently in progress where a variety of materials are considered, glasses, ceramics, oxide metals and so on[2-4]. The method to vary the transmittance in the glass plate is the surface processing with the convex and concave patterning using polymer template; the protective layer for solar cell devices is the object to work with it.[2] The method in oxide metals is the doping of $\mathrm{Ga}$, which aims for materials with low electrical conductivity and high optical transparency.[4] Furthermore, applying the electric field or external force is considered as the method to control the transmittance for liquid crystalline materials. [5-7] Those are, polymer-stabilised blue phase liquid crystal cell prepared to develop promising liquid crystal display with a fast gray-to-gray response time, the phase-separated composite film with UV curable optical adhesive, the composite of polymer dispersed liquid crystal films with iodine doped polyvinyl alcohol film.

In comparison with research works mentioned above, our experimental method is simple and easy, that is, to vary the light transmittance of the film is realised with only thermal ageing of PCB2A sample. While PCB2A is transparent in isotropic phase and opaque in nematic phase in equilibrium, it is still in transparent in nematic phase in non-equilibrium since the transition is slow. Moreover, the glass transition of the polymer makes the nematic state frozen with holding the optical properties. Therefore, it is expected that various thermal ageings for PCB2A in nematic phase can vary the transmittance of the film.

\section{EXPERIMENTAL}

\subsection{Materials}

The syntheses of the monomer are adapted from those of Litt et al.[8] and Shibaev et al.[9], 4-(Hydroxoethyloxy)-4'cyanobipheny (1) was prepared by refluxing 4-cyano-4'hydroxybiphenyl and ethylene carbonate with tetraethylammonium bromide as a catalyst in dimethylformamide solution at $160^{\circ} \mathrm{C}$ for $7 \mathrm{~h}$. After the reaction was over, the mixture was poured into water, then the residue was dissolved in ethyl acetate and the whole was shaken. The organic layer was separated, washed with water repeatedly. The residue after evaporation was three times recrystallised from benzene. Yield: $70 \%$. The compound was identified with the i.r. spectrum following characteristic absorption and 1H NMR spectrum.

The monomer, 6-(4'-cyanobiphenyl-4-yloxy) ethyl-acrylate (2) was obtained by acylation of (1) with the acid chloride of acrylic acid in the presence of triethylamine in absolute tetrahydrofuran at room temperature. After the reaction, tetrahydrofuran was evaporated, then the residue was dissolved in methylene chloride, it was washed with water and dried with $\mathrm{MgSO}_{4}$. The methylene chloride was evaporated, and the substance was recrystallised from methanol. Yield: $70 \%$. The product was identified with the i.r. spectrum and $1 \mathrm{H} \mathrm{NMR}$ spectrum. 
The i.r. spectrum of the compound (1) showed the following characteristic absorptions $\left(\mathrm{cm}^{-1}\right): 3300(\mathrm{OH}$ broad); $3100(\mathrm{C}-\mathrm{H}$ aromatics $)$; $2230(\mathrm{C} \equiv \mathrm{N}) ; 1680,1500(\mathrm{C}-\mathrm{C}$ aromatics); $1250, \quad 1070$ $(\mathrm{C}-\mathrm{O}-\mathrm{C}) ; 830(\mathrm{C}-\mathrm{H}$ aromatics $)$. For the compound (2), 3100 $(\mathrm{C}-\mathrm{H}$ aromatics $) ; 2220(\mathrm{C} \equiv \mathrm{N})$; $1720(\mathrm{C}=\mathrm{O}) ; 1600,1500(\mathrm{C}-\mathrm{C}$ aromatics $) ; 1250,1070 \quad(\mathrm{C}-\mathrm{O}-\mathrm{C}) ; 820 \quad(\mathrm{C}-\mathrm{H}$ aromatics). The $1 \mathrm{H}$ NMR measurements resulted in the well-defined spectra with characteristic resonant peaks(ppm). For the compound (1), 7.69-7.00(8H, m., $\mathrm{H}-\mathrm{C}$ aromatics); $4.12\left(2 \mathrm{H}\right.$, s., $\left.-\mathrm{CH}_{2}-\right) ; 1.53\left(2 \mathrm{H}\right.$, s., $-\mathrm{CH}_{2}-$ ), where $\mathrm{m}$. and $\mathrm{s}$. denote multiplet and singlet peaks, respectively. For the compound (2), 7.67-7.00 (8H, m., $\mathrm{H}-\mathrm{C}$ aromatics); 6.46-5.85 $(3 \mathrm{H}, \mathrm{m} .,-\mathrm{CH}=\mathrm{CH} 2) ; 4.54-4.24\left(4 \mathrm{H}, \mathrm{s} .,-\mathrm{CH}_{2}-\right)$.

In addition, the results of elemental analyses for the monomer (2) were as follows; $\mathrm{C}_{18} \mathrm{H}_{15} \mathrm{O}_{3} \mathrm{~N}(293)$ Calc.: C73.72; H5.12; N4.78. Found: C76.69; H4.44; N5.52.

PCB2A was prepared by radical polymerisation in an absealed ampoule for $30 \mathrm{~h}$ at $60^{\circ} \mathrm{C}$ with a radical initiator, $\alpha, \alpha$-azobisisobutyronitrile. A mixture of toluene and dimethyl sulfoxide was used as the polymerisation solvent. After the polymerisation, the solution was poured into tetrahydrofuran, and then PCB2A was purified by repeated precipitation from a tetrahydrofuran solution added to methanol. The polymer was fractionated by GPC equipped with a fraction collector. The weight-average molecular weight $\left(M_{\mathrm{w}}\right)$ of each fractionated polymer was determined by GPC calibrated with polystyrene standards. The molecular weight and the index of distribution, $M_{\mathrm{w}} / M_{\mathrm{n}}$ of fractionated samples are summarised in Table I, together with other properties.

\subsection{Methods}

Microscope observation was carried out with OLYMPUS AX-70 equipped with Mettler-Toledo FP90 hot stage and a laser power meter(PM-210, Nihon Kagaku, Eng.) The range of the power meter used to measure was $10 \mathrm{mV}$. The lump voltage of $\mathrm{AX}-70$ was fixed to $7.2 \mathrm{~V}$. It has a magnification of $200 . \quad T_{\mathrm{g}}$ (glass transition temperature), $\quad T_{\mathrm{N}-\mathrm{I}}$ (nematic-isotropic transition temperature) shown in Table I were obtained by DSC heating curves (heating rate $=5^{\circ} \mathrm{C} / \mathrm{min}$ ) recorded with SEIKO DSC200. GL-Sciences GPC system with 504R differential refractometer was used to determine molecular weight of fractionated PCB2A sample.

Film samples were prepared with a melt press procedure; PCB2A powder was gathered together using a Teflon closer and heated to $150^{\circ} \mathrm{C}$ to be pressed with glass cells, then it was quenched by immersing into ice water to prepare the film.
The powder sample is fixed to approx. $10 \mathrm{mg}$ so that the size of film specimen is kept constant. The shape of film is circle (the diameter is approx. $8 \mathrm{~mm}$ ), thickness is approx. $50 \mu \mathrm{m}$ (see Table I).

\section{RESULTS AND DISCUSSION}

3.1 Phase Behaviour

The results of $T_{\mathrm{g}}$ and $T_{\mathrm{N}-\mathrm{I}}$ can be compared with cyanobiphenyl acrylate polymer of different spacer lengths $(n)$. The transition temperatures for samples of $n=6$ and 11 are reported previously; as a result, $T_{\mathrm{g}}$ decreases and $T_{\mathrm{N}-\mathrm{I}}$ increases with the increase in $n$. In other words, the temperature range of liquid crystalline phase becomes wider as the increase in $n$, which propensity was the same as reported in many literature.[10-12]

The transition from isotropic to nematic phase was not plain. Figure 1 shows the cooling DSC curve at a rate of $0.1{ }^{\circ} \mathrm{C} / \mathrm{min}$ for P2A_2, P2A_3 and P2A_4 samples. It is obvious that the exothermic peak at $T_{\mathrm{N}-\mathrm{I}}$ has disappeared for sample of P2A_2, whereas P2A_3 and $\mathrm{P} 2 \mathrm{~A} 4$ remain $T_{\mathrm{N}-\mathrm{I}}$ peaks. Note that this DSC results do not mean the disappearance of the transition from isotropic to nematic phase for P2A_2. In order to ensure the isotropicnematic transition for $\mathrm{P} 2 \mathrm{~A} 2$, polarised optical microscope(POM) observation with a temperature jump between 105 and $90^{\circ} \mathrm{C}$ was carried out. It was found to take approx. $75 \mathrm{~min}$ after the jump to $90^{\circ} \mathrm{C}$ to observe the refraction from $\mathrm{P} 2 \mathrm{~A} 2$ film under the crossed Nicoles as an evidence of the nematic liquid crystal. Namely, it takes relatively long time to form nematic phase against cooling. The slow phase transition is the reason for disappearance of $T_{\mathrm{N} \text {-I }}$ peak seen in the DSC results.

\subsection{Light Transmittance}

Various thermal ageing processes were applied to the films prepared with PCB2A samples listed in Table I, and then the transmitted light volume of the film was measured. The film placed on a glass substrate was at first maintained at $T_{2}\left(=150^{\circ} \mathrm{C}, T_{2}\right.$ is well higher than $T_{\mathrm{N}-\mathrm{I}}$ ), then kept at $T_{3}$ with the ageing time of $t_{3}$. After the ageing process, it was quenched with ice water and taken for the transmittance measurement.

The measurement was carried out for the field of microscope without the crossed Nicoles, the results are shown as plots of $\left(I / I_{0}\right)$ vs $T_{3}$ in Figure 2. $\quad I_{0}$ is the intensity of the transmitted 
light for the glass substrate alone, $I$ the intensity with the film specimen.

$\left(I / I_{0}\right)$ values for film specimens prepared from the fractionated samples are invariant for $T_{3}$ lower than approx. $70^{\circ} \mathrm{C}$. For $T_{3}$ higher than $70^{\circ} \mathrm{C}$, the plot shows a peak with the variation of $T_{3}$, this ends at approx. $100^{\circ} \mathrm{C}$. The peak height is closely related with $t_{3}$; the longer $t_{3}$ is, the lower the light transmittance is. The propensity is clear for the films of P2A_2 and P2A_3, whereas it is less clear for P2A_4. Furthermore, for the film of the unfractionated sample, the temperature region where $\left(I / I_{0}\right)$ do not vary is ambiguous; that is, the broad peak appears over the experimental temperature range. From these results, it is seen that the relation between $\left(I / I_{0}\right)$ and $T_{3}$ is much influenced by the molecular weight and the molecular weight distribution. By adopting suitable values of $T_{3}$, $t_{3}$, the molecular weight, we can control $\left(I / I_{0}\right)$ for the film; as the examples of a transparent and an opaque film, the microscope images are shown in
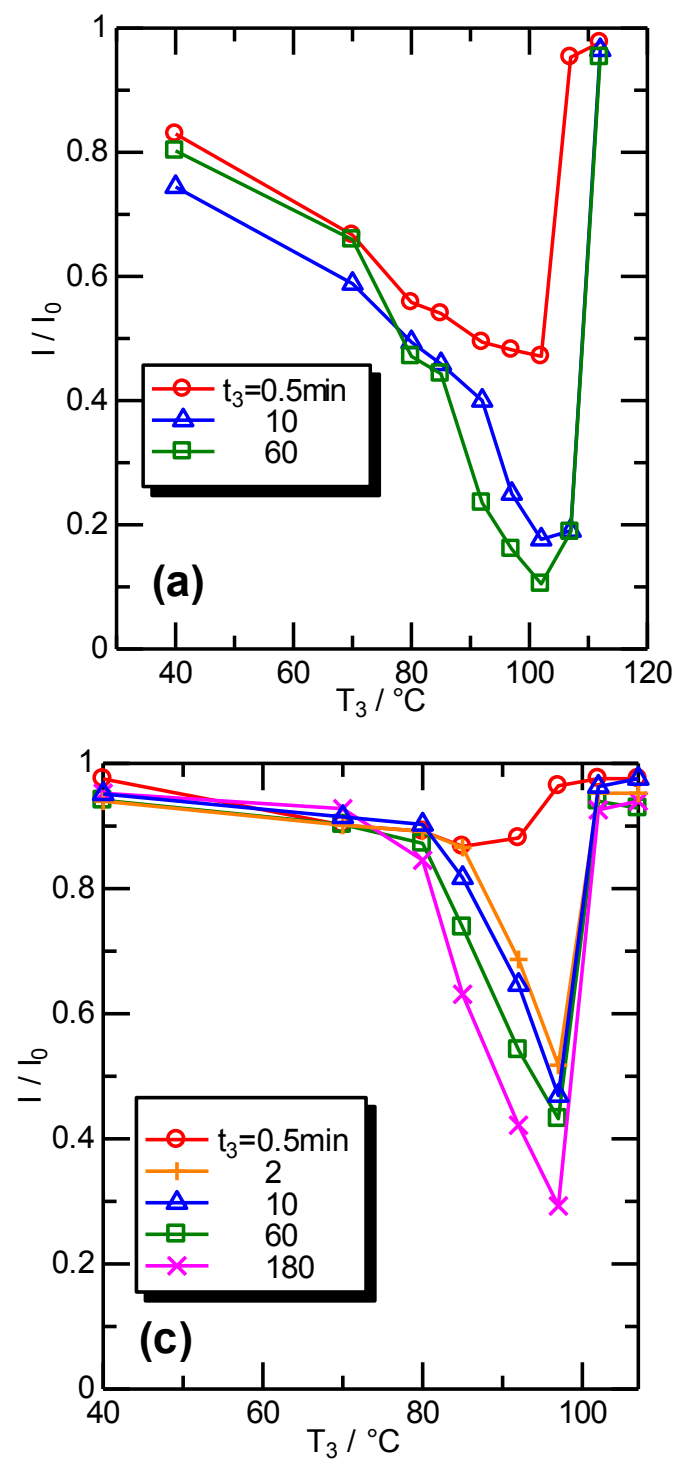

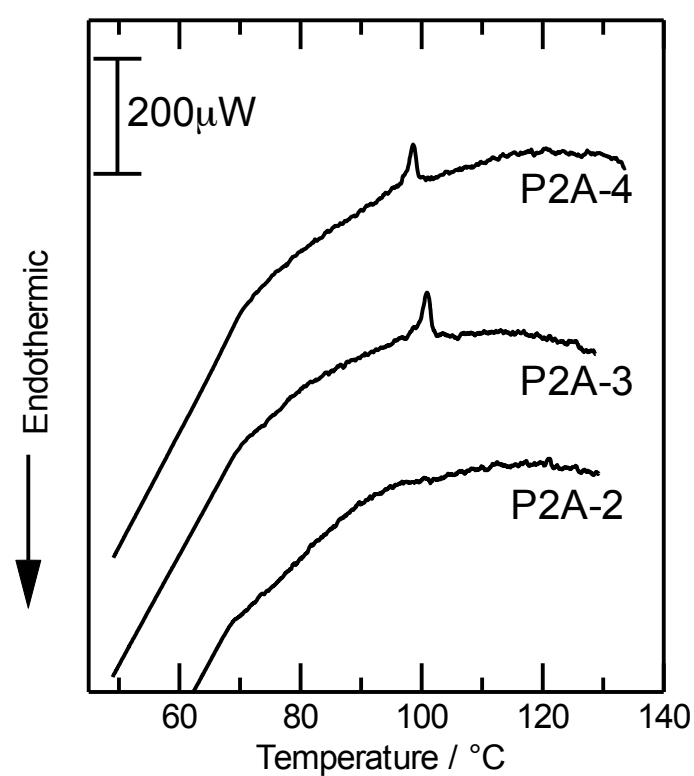

Figure 1. DSC thermograms of cooling scans at a rate of $0.1^{\circ} \mathrm{C} / \mathrm{min}$ for $\mathrm{PCB} 2 \mathrm{~A}$ samples.
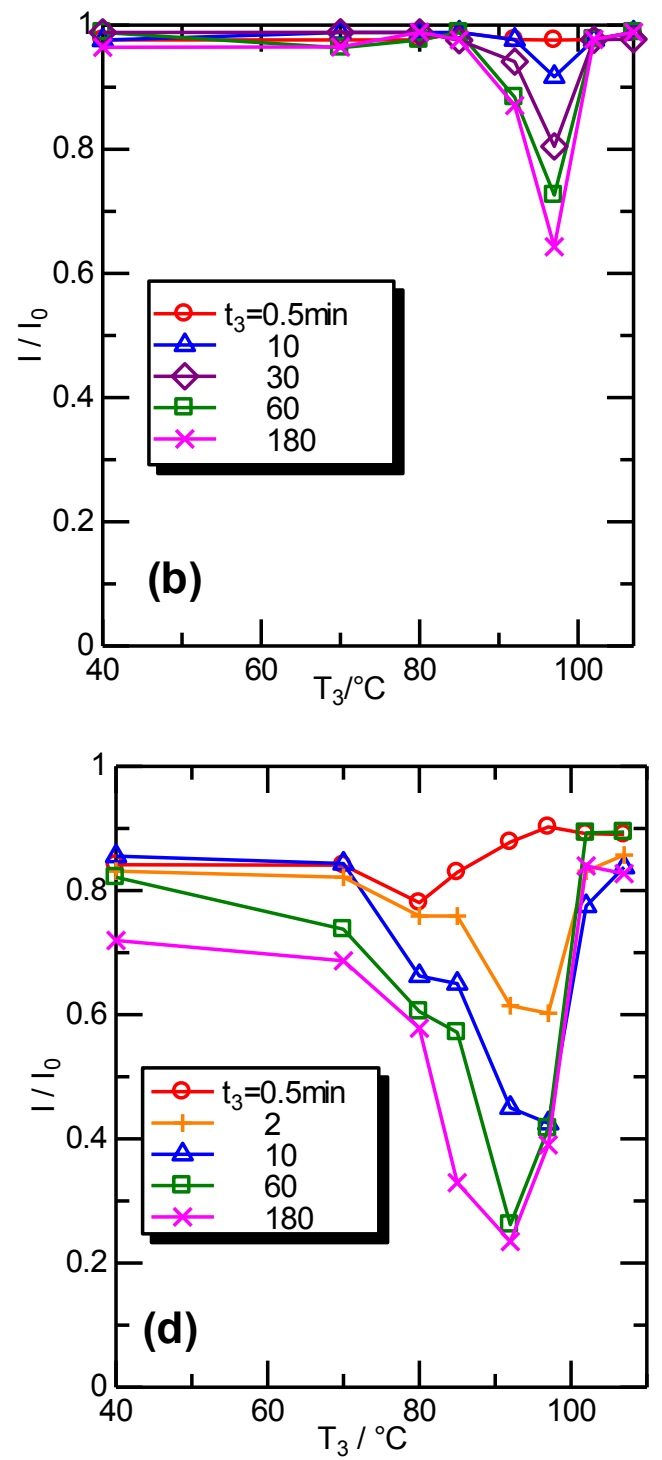
Figure 3 for the specimen prepared from the unfractionated sample with $t_{3}=60 \mathrm{~min}$.

For the film of P2A 4, which has the lowest molecular weight, the appearance of the peak of $\left(I / I_{0}\right)$ plot is worst unclear among the three fractionated samples. The reason for this result is currently not obvious; it might be related with the low molecular weight.

For the films of P2A_2 and P2A_3, the peaks of $\left(I / I_{0}\right)$ plots clearly appeared. The ageing at the temperature higher than the peak, i.e. $T_{3}>100^{\circ} \mathrm{C}$ means that the specimen is quenched from the isotropic phase; that is, the isotropic state is fixed to the film, and consequently it results in a transparent film. When $T_{3}$ is lower than $70^{\circ} \mathrm{C}$, the specimen is rapidly cooled from $T_{2}$ to $T_{3}$, which also means that the isotropic state is fixed to the specimen because $T_{3}$ is lower than $T_{\mathrm{g}}$. Contrastively, when $T_{3}$ is between c.a. 80 and $100^{\circ} \mathrm{C}$, the nematic state is fixed to the film after the quench. This is the reason for the decrease of $\left(I / I_{0}\right)$ in the region of c.a. $80<T_{3}<100^{\circ} \mathrm{C}$.

If we focus on the plots of $t_{3}=10 \mathrm{~min}$ for the fractionated samples, it becomes understandable for the effect of molecular weight on the kinetics of the nematic formation and thus on the transmittance of the film. More specifically, $\left(I / I_{0}\right)$ for $t_{3}=10 \mathrm{~min}$ of $\mathrm{P} 2 \mathrm{~A} \_2$ is distinguishable from those of $\mathrm{P} 2 \mathrm{~A} \_3$ and $\mathrm{P} 2 \mathrm{~A} \_4$, in the $T_{3}$ region where the peak appears; $\left(I / I_{0}\right)$ significantly decreases for P2A_3 and P2A_4. The decrease in $\left(I / I_{0}\right)$ implies that the nematic formation is considerably in progress in the ageing of $10 \mathrm{~min}$. For P2A_2, $t_{3}=10$ is not enough to form nematic phase, and consequently $\left(I / I_{0}\right)$ values are still close to 1. These results are in accordance with DSC thermograms of cooling scans shown in Figure 1 .

$T_{3}=97^{\circ} \mathrm{C}$ was the peak top of the $\left(I / I_{0}\right)$ plot for P2A_3, then $\left(I / I_{0}\right)$ values approach to 1 with the decrease in $T_{3}$. The lower $T_{3}$ is, the slower the nematic phase forms, which contributes to the increase in $\left(I / I_{0}\right)$. Accordingly, it is possible to control the transmittance for the PCB2A film.

\section{CONCLUDING REMARKS}

In the variation from isotropic to nematic states of PCB2A, a slow transition was observed for the sample of the higher molecular weight $\left(M_{\mathrm{w}}\right)$. The exothermic peak in DSC curve disappeared for the higher $M_{\mathrm{w}}$ sample, whereas the DSC peaks appeared as usual for the lower $M_{\mathrm{w}}$ sample.

Transparent/opaque changes for the films prepared from samples of different $M_{\mathrm{w}}$ were investigated. In consequence, the transparent/ opaque change enables us to control the transparency of PCB2A film by means of a simple thermal treatment.
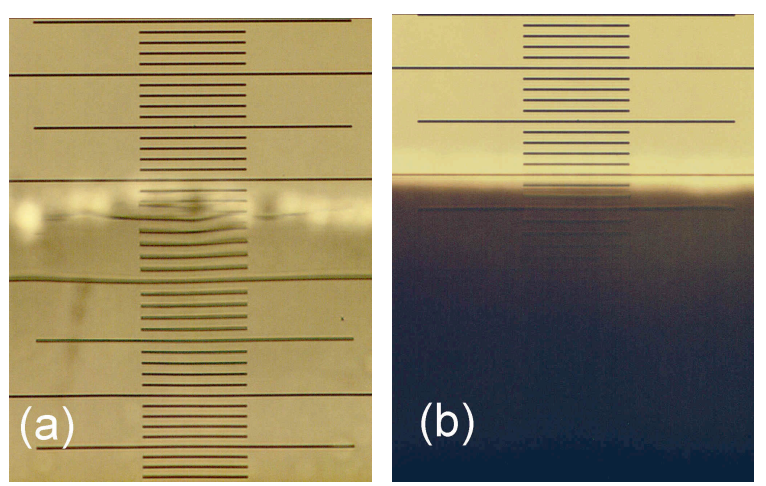

Figure 3. Pictures of the microscopic observation to demonstrate the transparent/opaque change of the film of unfractionated sample covering the microscale of $10 \mu \mathrm{m}$. $t_{3}=60 \mathrm{~min}$ (a) $T_{3}=40^{\circ} \mathrm{C}$, (b) $T_{3}=102^{\circ} \mathrm{C}$. The size of the picture; $450 \mu \mathrm{m}$ in height and $350 \mu \mathrm{m}$ in width.

\section{REFERENCES}

[1] S. P. Papkov, Adv. Polym. Sci., 59, 75-102 (1984)

[2] K. S. Han, J. H. Shin, H. Lee, Solar Energy Materials Solar Cells, 94, 583-587(2011)

[3] L. An, A. Ito, T. Goto, Mat. Lett., 65, 3167-3169(2011)

[4] Y. Takemoto, M. Oshima, K. Yoshino, K. Toyota, K. Inaba, K. Haga, K. Tokudome, $J$. J. Appl. Phys., 50, 088001(2011)

[5] Yong-Huu Kim, Sung-Teak Hur, Chang-Sub Park, Kyung-Woo Park, Suk-Won Choi, Shin-Won Kang, Hak-Rin Kim, Opt. Express, 19(18), 17427-17438(2011)

[6] Chong-Yin Wu, Chen-Yu Tang, W. Lee, Appl. Phys. Express, 3, $111701(2010)$

[7] I. Amimori, N. V. Priezjev, R. A. Pelcovits, G. P. Crawford, J. Appl. Phys., 93(6), 32483252(2003)

[8] M. H. Litt, W.-T. Whang, K. T. Yen, X. J. Qian, J. Polym. Sci. Pt.A: Polymer Chem., 31, 183-191(1993)

[9] V. P. Shivaev, S. G. Kostromin, N. A. Platé, Eur. Polym. J., 18, 651-659(1982)

[10] S. G. Kostromin, V. V. Sinitsyn, R. V. Tal'roze, V. P. Shivaev, Polymer Sci. U.S.S.R., 26(2), 370-382(1984)

[11] M. V. Piskunov, S. G. Kostromin, L. B. Stroganov, V. P. Shibaev, N. A. Platé, Makro. Chem. Rapid Commun., 3, 443-447(1982)

[12] S. Kurihara, T. Ikeda, S. Tazuke, Macromolecules, 26, 1590-1594(1993)

(Received 13 January 2012; Accepted 31 July 2012) 